\title{
José Nelson Mucha
}

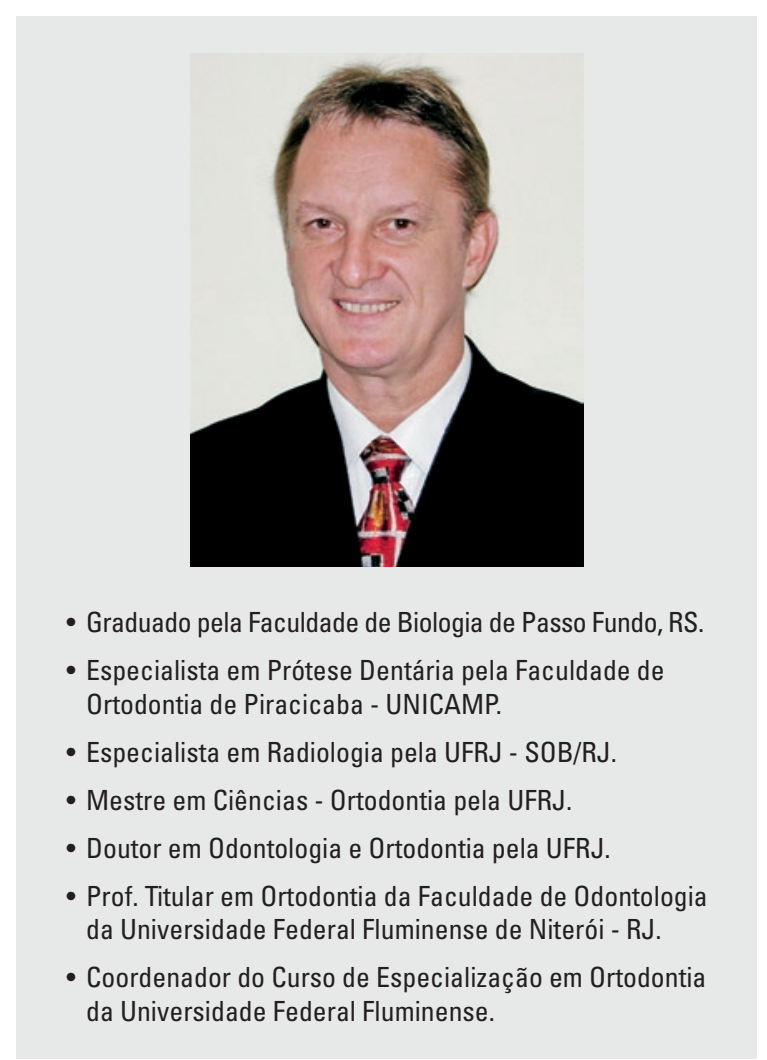

Nesta edição publicamos a esperada entrevista com o Prof. Dr. Nelson Mucha. Apresentar o Prof. Mucha significa apresentar a excelência da Ortodontia. Sua dedicação, seriedade, ciência e arte influenciaram e influenciam inúmeros ortodontistas que puderam ter a felicidade de ouvi-lo, ou de lerem seus artigos. Mesmo para aqueles que puderam ter apenas uma amostra de sua coleção de trabalhos e casos tratados com excelência percebem suas qualidades singulares. Por isto, muito nos honra publicar essa entrevista aqui enriquecida pelos ilustres entrevistadores Dr. Alberto Consolaro, Dra. Ana Maria Bolognese,, Dr. Estélio Zen, Dr. Guilherme Janson e Dr. Roberto M. Lima A. Filho.

O Editor
1) Como o senhor analisa a exacerbada valorização dos aparelhos sob prescrição e da multiplicidade de técnicas, tidas como tecnologias avançadas e significando "tratamento ortodôntico", em detrimento aos corretos diagnósticos e planejamentos? Ana Maria Bolognese

Em primeiro lugar deve dizer que fico honrado em poder participar da seção de entrevistas desta prestigiosa e conceituada revista. Em segundo lugar agradecer aos professores participantes, os quais representam o que a Ortodontia brasileira tem de mais significativo, o que me coloca numa posição de respeito e responsabilidade em estar a altura das expectativas e respostas a serem apresentadas. Em terceiro lugar, respondendo a esta pergunta, gostaria de fazer um exercício de retrospecção para entender como a Ortodontia evoluiu em relação aos tipos de aparelhos e em relação às técnicas disponíveis atualmente. Os autores que prescreveram aparelhos, tais como Andrews, Ricketts, Roth, Alexander, Bennett, Mc Lauglling entre outros, são profissionais da maior qualidade que tiveram uma formação ortodôntica clássica e tradicional, com ênfase no diagnóstico e planejamento dos casos. Com alta carga horária nos conceitos de crescimento e desenvolvimento crâniofacial, e nos procedimentos técnico-laboratoriais para a confecção dos aparelhos. Estamos falando das décadas de 50, 60 e 70 onde a confecção e montagem de um aparelho ortodôntico eram práticas que necessitavam de tempo e alta habilidade. Gostaria de enfatizar esta última característica, HABILIDADE. Portanto, todos estes grandes profissionais foram altamente treinados no sentido de desenvolverem uma habilidade para 
a confecção e montagem dos aparelhos, e conduzirem de maneira adequada os tratamentos ortodônticos, com a confecção individual de arcos para o correto desenvolvimento e finalização dos tratamentos. A partir de um domínio técnico e de habilidades é perfeitamente possível e justificável simplificar certos procedimentos para que se tenha maior rendimento e aproveitamento do tempo de consultório. A partir do conhecimento básico que estes profissionais apresentavam, e da experiência clínica pessoal, incorporaram modificações, desenvolveram estratégias e elaboraram artifícios técnicos de acordo com preferências pessoais, desenvolvendo os chamados aparelhos programados ou prescrições. Cada autor com a sua preferência de acordo com valores próprios pré-estabelecidos de média, ou normal. Repetindo, está se falando de média. Para se atingir a excelência na finalização será necessário incorporar dobras para se atingir o ideal individual. A minha opinião pessoal neste caso não é contra os aparelhos com prescrição, pois podem ser considerados uma evolução, mas sim contra a falta do treinamento básico imprescindível para a prática da boa Ortodontia. Sem o treinamento isto será impossível, pois estes aparelhos, como qualquer aparelho fixo, apresentam uma série de limitações tais como: imprecisões na montagem do aparelho; variações anatômicas; variações nas relações maxilomandibulares; necessidade de sobre-correções; variáveis mecânicas (o centro de resistência do dente está longe do ponto de aplicação da força; folga entre "slot" e braquete e diminuição das forças liberadas pelos arcos).

A partir daí, as empresas comerciais passaram a oferecer os aparelhos desenvolvidos pelos profissionais como se fossem resolver todos os problemas. Como existem tantas prescrições e técnicas a questão ainda é: qual a melhor qual é a que oferece o melhor resultado? A questão que aqui se apresenta é a qualidade dos serviços prestados que se espera que devam ser provenientes de um bom ortodontista. Que devem ser: a melhor qualidade no menor tempo e com o maior benefício ao paciente.
A Ortodontia é um ramo da Biologia e como tal, o tratamento deve estar embasado em conhecimentos dos princípios biológicos, diagnóstico criterioso, com todos os elementos necessários; planejamento com objetivos claramente definidos, tendo em vista excelência em: tecidos bucais saudáveis; função adequada; estética facial e dentária e; estabilidade dos resultados em longo prazo. Após a conclusão do tratamento e da remoção do aparelho, somente poderá ser afirmada a excelência no diagnóstico e planejamento e da correta utilização da mecanoterapia, ou o contrário. Um péssimo diagnóstico e planejamento com a utilização do melhor aparelho sem o adequado treinamento, resultará em tratamentos péssimos. Os dentes são estúpidos. Eles não conseguem entender o apelo do fabricante ou do líder carismático. Eles entendem de força ótima.

A resposta a sua pergunta objetivamente é: Tratase de comércio e leis de oferta e procura, e talvez na nossa falha ou omissão, como professores, em não alardear com maior ênfase estas verdades máximas aos consumidores (pacientes, dentistas e ortodontistas) de que os princípios básicos biomecânicos, diagnóstico, planejamento com definição clara de objetivos e o domínio técnico dos aparelhos são mais importantes do que os apelos dos fabricantes.

\section{2) Como professor de uma renomada uni- versidade, qual o conselho você daria para um estudante que pretende ingressar em uma Faculdade de Odontologia? Ana Maria Bolognese}

Por princípio me vejo como uma pessoa otimista, porém este otimismo está relacionado às expectativas criadas em relação a qualquer profissão, bem como as possibilidades dela vir a ser concretizada, e a oportunidade real de satisfação esperada, bem como a preparação e o desejo ou vontade que o estudante demonstra em relação à determinada carreira ou profissão. Através dos tempos, os anseios e as expectativas mudam em relação a qualquer profissão. Explicando melhor, diria que uma das melhores profis- 
sões do mundo atualmente, em termos financeiros, é ser dono da Microsoft, ou ser o Bill Gates, mas não adianta ter esta expectativa pois ela é improvável. Atualmente existem muitas profissões que oferecem um futuro promissor em relação à remuneração financeira, prestígio e bem estar. Certamente a Odontologia já foi uma profissão bem mais glamourosa e de maior retorno financeiro, portanto, espera-se que os futuros candidatos à carreira tenham consciência que existe uma saturação do mercado em relação aos tratamentos ditos especializados, mas com carências na parte de clínica geral. Com esta maior saturação do mercado, os rendimentos sejam naturalmente menores. Porém, em qualquer profissão, se o profissional realmente gostar do que faz, fizer com carinho e dedicação e em busca da excelência, com o objetivo de realmente atender ao paciente com o melhor trabalho, o retorno vai ocorrer. Este retorno será inicialmente na forma de gratidão e reconhecimento de seus pacientes e de seus colegas, e depois conseqüentemente com uma paga justa pelos seus serviços. Não vejo a possibilidade de ganhos elevados na profissão, mas uma forma digna de ganhar o sustento e de fornecer um serviço de qualidade.

Considero que existe a necessidade de maior quantidade de cursos técnicos, como os de prótese dentária, higienista e atendentes de consultórios odontológicos. Os higienistas poderiam fazer um excelente trabalho de conscientização da população, com um tempo de treinamento mínimo e com menores custos, como para a formação de um Cirurgião-Dentista e resultaria, como conseqüência, em uma grande contribuição para a melhora da saúde bucal da população, principalmente os de menor renda. Acredito que a criação destes programas (e que está sendo discutida pelo $\mathrm{CFO}$ ) melhoraria muita a situação da Odontologia. Porém, com os valores vigentes há a necessidade imperiosa da obtenção do título de doutor, ou então o indivíduo não será nada.

Objetivamente, responderia que o estudante deve ponderar as reais expectativas e conversar com pessoas egressas por mais tempo e principal- mente os recém egressos das Faculdades para que possam dar um depoimento realista da situação atual da Odontologia. Mas se, conhecendo as limitações e riscos do mercado, ainda assim considerar que a Odontologia é a profissão da sua vida, e que pretende exercê-la com amor, dedicação, desprendimento e total atenção à saúde bucal de seus pacientes, sem ter uma excelente retribuição financeira, vá em frente. O sol nasceu para todos.

\section{3) E para aquele estudante que está concluin- do a graduação em Odontologia e pretende fazer sua especialização em Ortodontia e Or- topedia Facial, que orientação você daria? Roberto Mario Amaral Lima Filho}

Procure conversar com os professores de sua Faculdade, aqueles considerados os educadores e não apenas professores. Também com os bons profissionais do mercado, aqueles que tem belos casos clínicos para mostrar para quem for fazer uma visita ao consultório. Aqueles que podem ser considerados exemplos de dedicação e com trabalhos bem realizados. Certamente as orientações serão no sentido de selecionar os cursos com carga horária de 2000 a 3000 horas, com 24 a 36 meses de duração, com a uma boa distribuição entre as atividades das ciências básicas, de treinamento básico e laboratorial, de atendimento clínico e de pesquisa. Com um corpo docente que esteja comprometido com todas estas áreas, para que possa ter um treinamento adequado.

Que ao se candidatar a um curso deste gabarito entenda que a concorrência será grande e que talvez não seja aprovado ou aceito para realizar o curso em uma primeira tentativa, mas a perseverança é uma qualidade que se espera de um bom ortodontista e que este tempo de espera para outras tentativas deve ser bem aproveitado. Como para o aprimoramento dos conhecimentos gerais da odontologia (Anatomia, Histologia, Embriologia, Fisiologia, Genética, Materiais Dentários, Patologia, Radiologia, Periodontia Odontopediatria e outras áreas comuns a Ortodontia), pois acre- 
dito que um excelente dentista será um excelente ortodontista. Que invista na experiência da prática clínica da Odontologia, ao atendimento de pacientes, pois isto será vital para o sucesso no seu treinamento no curso de Ortodontia.

Que procure desenvolver a habilidade manual e conhecimentos de Inglês e informática imprescindiveis para se manter atualizado e acompanhar qualquer curso.

Que não caia na tentação de fazer cursos rápidos e ditos preparatórios pois eles apenas visam angariar lucros dos candidatos ansiosos e ávidos por conhecimentos. Os bons cursos não levam em consideração os cursos preparatórios, pois tudo isto será ministrado novamente durante o curso em questão.

Que tenha uma visão realista do mercado, onde atualmente existe uma proliferação de cursos de final de semana, com ênfase nos aparelhos milagrosos e com forte apelo de marketing, e que vai acarretar em um primeiro momento numa concorrência desleal, mas que em longo prazo o reconhecimento e as recompensas virão. A Ortodontia é uma especialidade muito gratificante. Somos da área da saúde e atendemos aos pacientes mais saudáveis que existem. Jovens na sua plenitude de vigor, alegria e energia, e que apenas apresentam desarmonias dentárias ou esqueléticas.

\section{4) Qual a importância da cefalometria em seu planejamento ortodôntico? Guilherme Janson}

Como professor devo dizer que a cefalometria é uma excelente ferramenta de ensino, pois é quase impossível ensinar e descrever certas características das más oclusões sem recorrer à linguagem da matemática. Da mesma forma as pesquisas em relação aos padrões, diagnósticos e resultados de tratamentos, seriam impossíveis de terem respostas claras sem o auxílio da matemática que é fornecida pelas medidas obtidas pela cefalometria. Considero também a radiografia cefalométrica um valioso instrumento para comunicação entre o profissional e o paciente, para ilustrar os problemas e explicar as razões da terapêutica, bem como os objetivos a serem atingidos. Porém, como elemento de diagnóstico, a cefalometria ou as análises cefalométricas falham em informar a exata dimensão dos problemas, pois além de utilizarem medidas bidimensionais de um problema tridimensional, podem apresentar erros inerentes à tomada radiográfica, erros dos traçados, erros da localização dos pontos, erros da determinação das linhas, planos e obtenção das medidas, sejam elas manuais ou através de programas de computador, além das variações entre os indivíduos ao se aplicar normas ou medidas padrão. Além disto, qualquer análise está baseada em dados da média da população escolhida por determinado autor para descrever o problema, a partir da média considerada normal. Portanto, como clínico, prefiro me basear em dados mais subjetivos para a tomada de decisões e não em números absolutos. Exemplificando: considero como primordial na consulta inicial do paciente saber a sua queixa principal e conseqüentemente realizar uma boa anamnese, com adequada coleta de dados e, então, a análise das características faciais e dentárias deste paciente. Após então, com os dados obtidos das radiografias dentárias periapicais e dos modelos, procedo a uma confirmação, ou não, destas primeiras informações, através da análise cefalométrica. Esta avaliação então consistirá em determinar, por exemplo, se realmente existe uma desarmonia entre maxila e mandibula, e que até pode ser traduzida em números (ângulo ANB, SNA, SNB ou WITS). Se o problema vertical tem implicações esqueléticas (FMA, GoGn-SN, Eixo Y), e como estes planos faciais se apresentam espacialmente em relação à face total do paciente (algo como a análise de Sassouni). Posteriormente então, procedo a análise das relações dos incisivos inferiores em relação à face e à mandíbula (1-NB e IMPA). Caso a face apresente um bom aspecto, ou a relação dos tecidos moles entre o lábio inferior e mento estiverem harmoniosos, então o incisivo inferior deverá ser mantido naquela posição. Caso exista protrusão dos lábios tornando o aspecto facial desagradável, ou o lábio inferior estiver 
protruído ou evertido em relação ao mento, então os incisivos inferiores deverão ser retraídos. Para definir esta quantidade considero a linha "S" de Steiner um bom parâmetro, numa relação de 1:1 (Linha S-LI e 1-NB).

Resumindo: A ordem de prioridade é a seguinte: 1) A queixa do paciente; 2) Anamnese e coleta de dados na ficha de consulta. 3) A análise facial e dentária; 4) A análise das radiografias periapicais; 5) A análise dos modelos e 6) A confirmação das informações com a análise cefalomérica.

\section{5) Qual a sua opinião sobre os distalizadores intrabucais para a correção da Classe II? O Sr. os utiliza em sua clínica ou os recomenda aos seus alunos? Guilherme Janson}

A movimentação de molares para distal é algo fácil de ser conseguido, porém será crítica a manutenção dos resultados obtidos com qualquer forma de movimento para distal dos molares, quando da aplicação de força para retraírem-se os dentes anteriores. Considero os aparelhos extra-bucais e os implantes como sendo as abordagens mais controladas para garantir o controle efetivo de ancoragem, sendo capazes de manterem os molares em suas posições mais posteriores. Portanto, para se ter um efeito significativo e controlar este resultado, prefiro utilizar a força extra-bucal. Alguns aparelhos para movimentar os molares para distal utilizam apoio no arco inferior e, conseqüentemente, por uma questão de ação e reação de forças os dentes incisivos inferiores serão projetados anteriormente. Este efeito está fora dos meus objetivos de tratamento ortodôntico. Outro argumento é o de que como ortodontistas, somos essencialmente administradores de espaços, e muitas vezes a movimentação dos molares para distal requer espaço, tal como a extração dos segundos ou terceiros molares. Ora, é muito esforço para conseguir espaço à distal dos primeiros molares, instalar um aparelho que pode quebrar e causar injúrias ao paciente, conseguir os espaços e antão estabelecer alguma forma de ancoragem para manter estes dentes nes- ta posição e retrair os anteriores com o risco de perda de ancoragem. Prefiro então a força extrabucal ou extrações de pré-molares, no qual o tratamento será menos traumático, em menor tempo e com maior benefício ao paciente, provavelmente preservando os terceiros molares.

\section{6) O Sr. utiliza aparelhos funcionais em sua clí- nica e/ou departamento de Ortodontia? Por- que? Guilherme Janson}

O curso de especialização em Ortodontia da UFF tem duração de 30 meses, com carga horária de 2.130 horas, e considero que o ideal de um curso de Especialização seria de 36 meses, com 3.000 horas ou mais ${ }^{7}$. Não estou mencionando Curso de Mestrado ou Doutorado, pois tenho uma concepção um pouco diferente de como estes deveriam ser (com ênfase na pesquisa, com os instrumentos para análise e consumo da literatura científica, didática e pedagogia, e aprofundamento dos conhecimentos da área básica). Mas isto é um outro assunto. Não considero válido também os cursos ditos preparatórios, pois dentre os objetivo do curso de especialização que eu coordeno, pretende-se estabelecer muito claramente uma filosofia de tratamento ortodôntico. Após este aprendizado poderá e naturalmente acrescentará outras informações técnicas ou filosofia que considera relevantes para sua prática clínica. E se o candidato aprender outras filosofias de maneira incompleta, isto acarretará conflitos e divergências com dificuldades de análise e de aproveitamento. No último semestre do Curso, temos uma relação de seminários de Técnicas Ortodônticas e Filosofias de Tratamentos, com 18 a 20 itens que são pesquisados, analisados e apresentados pelos próprios alunos na forma de seminário seguido de debates. Onde também figuram os assuntos de Técnicas e Filosofias com Aparelhos Funcionais ${ }^{1}$. Temos portanto, uma discussão teórica, porém não na forma sistemática de aplicação clínica. Utiliza-se em alguns casos de grandes assimetrias (microssomia hemifacial), em fase de crescimento, ou mordidas cruzadas unilaterais reais, em que será necessário algum reposicionamento mandibular para evitar futuras cirurgias. 
Mesmo que a argumentação de que, com os aparelhos ortopédicos funcionais apresentaria uma melhor posição da mandíbula nos casos de retrusão mandibular, eu teria a dizer que com um bom controle vertical com aparelho extrabucal do tipo Klohen de tração alta, pode-se reverter esta tendência e ao final do tratamento estas características seriam imperceptíveis clinicamente. Após uma fase com a utilização dos aparelhos funcionais, será necessário, inevitavelmente, uma outra fase com aparelhos fixos. Nesta fase poderá ocorrer extrusões dentárias, perda da relação molar, e recidiva do que era apenas uma reposição mandibular e não uma remodelação condilar ou da fossa articular. E teremos novamente a necessidade de utilizar aparelhos para melhorar a relação molar. Com o aparelho fixo instalado ficará mais difícil retornar ao aparelho funcional e então a escolha ideal recairá sobre os aparelhos extrabucais.

Ao se analisar mais criteriosamente os efeitos dos aparelhos ortopédicos funcionais (para a correção da Classe II), que estão indicados para os casos de: a) dentição mista, b) com bom potencial de crescimento, c) com boa resultante de crescimento (mais horizontal), d) com possibilidade de projetar incisivos inferiores (o que é raro) e e) não necessitar de aparelho extrabucal, tem-se que praticamente todos vão apresentar um apoio ou grampo para restringir o movimento do primeiro molar superior para mesial, ou até para incliná-lo ou movimentá-lo para distal. Terão um dispositivo ou alívio para permitir a migração e extrusão do primeiro molar inferior para mesial (no espaço ocupado pelo segundo molar temporário). Terão um grampo para verticalizar os incisivos superiores e terão algum apoio ou dispositivo contra o rebordo anterior inferior, o qual projetará por inclinação ou de corpo os incisivos inferiores para labial. Ora, até aqui está se falando em movimentos dentários. Com o reposicionamento mandibular poderá haver uma remodelação ou não dependendo de características muito específicas de cada paciente, com variações individuais.
Respondendo mais categoricamente, não utilizo na minha clínica, por considerar que o resultado que eu obtenho com as formas tradicionais de tratamento da Classe II, com força extrabucal do tipo Klohen, cervical ou alta, são excelentes, em menor tempo e com menor custo, pois seriam necessários praticamente dois tratamento para resolver apenas um problema do paciente.

\section{7) Como você determina a época para iniciar o tratamento ortodôntico? Estélio Zen}

Em primeiro lugar, o período em que praticamente todos os problemas ortodônticos são mais bem diagnosticados, orientados e prevenidos é, indiscutivelmente, a fase da dentição mista tais como: controle de saúde bucal, restaurações adequadas, controle periodontal e orientação de técnicas de escovação, controle de hábitos, correções de mordida cruzada posterior e anterior e tratamento ou controle da má oclusão de Classe III. Fora estes problemas considero que a melhor fase, inclusive para o controle de espaços é a fase final da dentição mista, pois ainda estarão presentes os segundos molares temporários, e será possível aproveitar o "Lee Way Space", para a correção de apinhamentos suaves ou moderados. Está época situa-se após a erupção dos caninos permanentes e o aproveitamento do potencial inerente a este arco dentário, para o aumento inclusive da distancia entre os dentes caninos temporários.

Em segundo lugar a sua pergunta poderia ensejar a questão do tratamento ortodôntico em uma fase ou duas fases. Procuro tratar todos os pacientes em apenas uma fase (exceto os problemas descritos acima), definindo que a melhor época é a fase final da dentição mista.

Para os problemas de Classe I com falta de espaço, Classe I com espaços generalizados ou Classe I com Biprotrusão, a melhor fase é a dentição permanente.

Para os problemas de Classe II, nas meninas o início situa-se entre os 9 aos 11 anos e nos meninos entre os 11 e 13 anos, que vai coincidir com a 
época de maior crescimento. Portanto, nas meninas será a fase final da dentição mista e início da dentição permanente, e os meninos praticamente na dentição permanente.

Repetindo, prefiro iniciar os tratamentos com problemas de espaço considerados suaves e moderados, na fase final da dentição mista, após a erupção dos caninos permanente e antes da esfoliação dos segundos molares temporários (aproveitamento do Lee Way Space). Com isto os tratamentos em mais de $90 \%$ dos casos será resolvidos em apenas uma fase $^{2,4}$, com o tempo de aproximadamente 1 ano a $1 \frac{1}{2}$ ano ainda na fase de dentição mista e erupção dos dentes permanentes e mais 1 ano a $1 \frac{1}{2}$ ano na fase de dentição permanente. $\mathrm{O}$ meu tempo médio de tratamento é de 30 meses, variado de 24 a 36 meses, muito bem definido, com o paciente e responsáveis, e sem a necessidade de planejar outros tratamentos no futuro, para resolver os demais problemas remanescentes. Até por que eu teria dificuldades em definir diversos preços de diferentes tratamentos.

\section{8) Você usa aparelhos programados? Como? Quando? Estélio Zen}

Esta pergunta em parte já foi respondida na pergunta formulada pela Dra. Ana Maria Bolognese. Mas tentando esclarecê-la mais ainda, considero vital para o sucesso do tratamento ortodôntico, tendo em vista principalmente uma excelente finalização, definir muito claramente como montar o aparelho. Ou seja, programar os detalhes da montagem do aparelho. Para tanto, ao profissional que está se iniciando na profissão, considero muito importante um ensaio em modelos (set-up), para avaliar as possibilidades de tratamento e os detalhes que deverão ser levados em conta para se atingir a excelência na finalização. Este ensaio deve ser feito de maneira rigorosa, caso contrário, os dados não poderão ser obtidos de maneira precisa. Após então o ensaio em modelos, podese definir as alturas dos acessórios ortodônticos, as inclinações dos acessórios, como por exemplo nos dentes anteriores superiores, o posicionamento dos acessórios nos casos de extrações para favorecer o fechamento de espaços e obter um excelente paralelismo radicular e também favorecer a reforço ou perda de ancoragem. Se isto é aparelho programado para a eficácia do tratamento, uso-os sim. Por outro lado os aparelhos com programações de fábrica, não faço uso deles, pois elas são apenas médias, como também é média a forma de fabricação de um aparelho sem programação nenhuma. Programo também os diversos arcos que serão utilizados naquele caso especificamente e com as dobras e modificações necessárias para se atingir uma excelente finalização.

9) Apesar das reconhecidas limitações estéticas e funcionais dos implantes dentários em casos de anodontia parcial de incisivo lateral superior em pessoas com idade inferior a 2325 anos, esta conduta ainda é muito adotada no meio odontológico. Qual sua experiência sobre as conseqüências estéticas da colocação de implantes de incisivos laterais superiores em idades inferiores a 18 anos? Como corrigí-las? Quais seriam as opções para esperar a idade mais adequada para os implantes na região superior anterior? Alberto Consolaro

A utilização de implantes para substituir incisivos laterais ausentes é um assunto, na minha opinião, muito paradoxal, senão vejamos: para colocar um implante é necessário um espaço mésiodistal, de pelo menos 3,5 a $4 \mathrm{~mm}$ para o implante e de mais $1,5 \mathrm{~mm}$ de cada lado $(4+3=7 \mathrm{~mm}$ pelo menos). Esta largura de $7 \mathrm{~mm}$, é muitas vezes, maior do que a largura do lateral. Se um espaço maior for aberto, haverá melhores condições para a colocação do implante, porém haverá naturalmente uma remodelação com diminuição da altura óssea. Conseqüentemente a papila gengival terá uma retração pois só existe papila quando do ponto de contato até a crista óssea houver uma distância de $5 \mathrm{~mm}$ ou menos. Poderá se trabalhar no perfil de emergência para contornar este problema. Mas esteticamente a situação ficará comprometida pois 
o incisivo ficará com maior largura na região cervical. Ao se deixar a forma do incisivo mais estreito na região cervical para criar uma ilusão de ótica de dente mais estreito, faltará papila. Para ter papila, novamente, existe a necessidade de se ter crista óssea.

Vamos adiante. Para abrir o espaço haverá perda óssea. Ao se manter o espaço aberto desde a adolescência até 25 anos de idade, vai ocorrer maior perda óssea ainda. Ao se abrir o retalho para a colocação do implante vai ocorrer perda óssea. Ao se fazer enxerto de gengiva ou enxerto ósseo terá que se fazer uma estimativa das reabsorções ósseas que ocorrerão para se ter um aspecto estético aceitável. Está se falando de 3, 4 ou 5 intervenções cirúrgicas para a colocação do implante, que a longo prazo poderá ter reabsorções ósseas deixando exposto este implante ${ }^{8}$.

Nos casos de ausências de laterais superiores com má oclusão de Classe II, ou tendência à relação de Classe II, com boa forma de caninos, considero que a substituição dos laterais ausentes pelos caninos a melhor solução $0^{5,6}$.

Para os casos de Classe I e que se planeja a colocação de implantes, teoricamente, a melhor solução seria a manutenção dos caninos no local dos laterais até o final real do crescimento do paciente, deixando espaços no lado distal do canino, com algum recurso protético, para então nesta época movimentar os caninos para o espaço que eles devem ocupar, eliminando o recurso protético e realmente preparando o espaço para o implante. Conseqüentemente haverá osso em altura e espessura suficiente para a colocação de um implante na área do lateral. Só que esta situação é hipotética e acho pouco provável que o paciente aceite esta alternativa de bom grado.

Resumindo, estamos diante de paradoxos: se for realizado precocemente haverá problemas na altura cervical e bordas incisais; se o espaço for mantido por muito tempo haverá perda óssea; se os caninos forem mantidos no local dos laterais até o final do crescimento, haverá problemas estéticos neste período, com a necessidade de manter o espa- ço na distal destes com provisórios e será necessário um novo tratamento ortodôntico nesta época, para preparar o espaço para o implante e prótese.

Conclusão. Prefiro pensar primeiro em substituir os laterais pelos caninos e só então como último recurso, resolver com os implantes em uma idade adequada.

10) Em casos de anodontia parcial ou de perda dentária por traumatismo na região superior anterior, qual a sua experiência dos transplantes dentários autógenos como opção terapêutica em um contexto ortodôntico? Considerando a experiência bem sucedida dos ortodontistas escandinavos neste campo, no Brasil há disponibilidade suficiente de cirurgiões habilitados na técnica dos transplantes dentários autógenos que possam ser acionados pelos ortodontistas? Em sua opinião quais seriam as principais dificuldades para esta técnica ser mais difundida em nosso meio e quais as suas sugestões para superálas? Alberto Consolaro

A possibilidade de sucesso de transplante dentário autógeno é muito alta, atingindo mais de $80 \%$, quando realizada com o dente a ser trasplantado com até $2 / 3$ da raiz formada. Pode-se transplantar o dente até com a raiz parcialmente formada, mas desde que tenha o ápice francamente aberto. Temos alguns casos bem sucedidos e realizados na UFF, com o cirurgião Dr. Paulo José Medeiros.

Portanto, respondendo a segunda parte da pergunta, temos sim cirurgiões habilitados, pois a técnica é relativamente simples, e nos casos de trauma em que o alvéolo receptor não apresentar evidencia de lesão inflamatória aguda, o dente pode ser transplantado em um único tempo cirúrgico. Havendo processo agudo associado, o procedimento envolve a preparação de um leito para o futuro transplante, aguardando-se a formação de um tecido de granulação de 1 a 2 semanas (por volta de 15 dias) e ai então o dente é transplantado para o local definitivo. Este tecido de granulação será o 
responsável para a futura formação do ligamento periodontal deste dente. Os dentes com até $2 / 3$ de raiz formada terão o restante da raiz formada sem maiores problemas e com vitalidade pulpar. Um dos problemas que poderá ocorrer será a necessidade de realizar tratamento endodôntico, face a não reparação do tecido pulpar neste novo local, e em dentes com raízes praticamente formadas.

Uma das razões para esta técnica simples, econômica, rápida e com alto grau de sucesso se deve ao mito criado com os implantes de que eles são a solução a todos os problemas. Sabe-se que os implantes também apresentam alguns problemas. Outro aspecto devido à pouca aceitação ou utilização é o fato de que este procedimento é pouco compensador financeiramente, pois não existem custos agregados, como materiais e equipamentos especiais para a sua realização. A maneira de mudar esta situação é com a divulgação dos resultados e demonstrando as evidencias dos procedimentos através dos meios de divulgação, como as revistas científicas.

11) Qual a sua experiência quanto à freqüência das reabsorções dentárias associadas ao movimento ortodôntico e quais suas condutas predictivas e preventivas mais eficazes em sua prática clínica? Neste contexto, qual sua visão clínica sobre os melhores resultados, quanto à gravidade e freqüência de reabsorções radiculares, quando após 6 meses de tratamento se propicia um descanso de não ativação dos aparelhos por 2 a 3 meses? Alberto Consolaro

Considero que a freqüência de reabsorções perceptiveis radiograficamente associadas ao tratamento ortodôntico situam-se entre 10 a $15 \%$ dos casos. Este número está muito próximo da freqüência de reabsorções em indivíduos que não foram submetidos a tratamento ortodôntico ${ }^{3}$.

Destes 10 a 15\% de casos de reabsorções, $10 \%$ são os casos mais graves. Ou seja, afirmaria que $1 \%$ do total dos casos da clínica apresentam algum tipo de reabsorção mais preocupante, e a forma de mi- nimizar esta ocorrência seria no sentido de: evitar movimentos indesejáveis (mecânicas ortodônticas de ida e volta); evitar tratamentos muito longos; eliminar os hábitos, e pressões anormais; procurar utilizar elásticos intermaxilares apenas como um último recurso e na fase de finalização; evitar traumas, ou prematuridades, entre os dentes incisivos na retração dos dentes anteriores (a- retrair primeiro os incisivos inferiores, b- reduzir a sobremordida para depois, c- reduzir o transpasse horizontal); Não utilizar fios muito rígidos ou muito espessos, ou utilizar os que apresentem folga entre "slot" e fio. Isto eliminará ações ou efeitos indesejáveis na maioria dos dentes, mesmo que em alguns dentes esta força seja alta; caso não seja necessário controle de torque, os fios redondos podem e devem ser utilizados com sucesso; estabelecer a forma dos arcos de ligas metálicas, de acordo com a forma da arcada dentária, para serem repetidamente utilizadas durante todas as fases do tratamento para evitar movimentos contra as corticais ósseas.

Considero que a associação dos seguintes fatores como determinantes da maior reabsorção: o tempo de tratamento $\mathrm{x}$ o tipo de movimento (torque, intrusão e translação, nesta ordem) x a extensão do movimento $\mathrm{x}$ forma radicular $=$ maior possibilidade de reabsorções.

Quanto a última parte da sua pergunta, se o tempo de espera seria um fator para minimizar as reabsorções, diria que isto é uma falácia. Explicando melhor. Diante de uma constatação, após 6 meses ou um ano de tratamento, de reabsorções severas nos incisivos superiores, qual seria o procedimento a ser adotado? Não movimentar os dentes envolvidos! Neste caso a minha conduta e recomendação seriam remover o aparelho destes dentes, continuar o tratamento nos demais dentes no sentido de obter uma excelente intercuspidação dos dentes posteriores e então, após aproximadamente 6 ou 12 meses, incluir novamente os dentes anteriores no aparelho e alinhar e nivelar estes dentes, fechar espaços se necessário, e no menor tempo possivel finalizar o caso e "esplintar" estes dentes. 
Com este procedimento estamos minimizando as ações de forças, as reverberações dos arcos ortodônticos ("rebounding", idas e voltas dos efeitos dos arcos ortodônticos, mesmo que mínimas) e o tempo de ação das forças sobre estes dentes. Não é o tempo de espera e o reparo que fará com que não mais ocorram as reabsorções no futuro, mas o

\section{Alberto Consolaro}

- Graduado pela UNESP.

- Especialista em Patologia Bucal pelo CFO.

- Mestre em Biologia e Patologia pela UNICAMP.

- Doutor em Diagnóstico Oral pela USP.

- Livre Docente em Patologia pela USP.

- Professor Titular em Patologia da USP.

\section{Guilherme R. P. Janson}

- Professor Associado da Disciplina de Ortodontia da Faculdade de Odontologia de Bauru - Universidade de São Paulo.

- Pós-Doutorado na Universidade de Toronto, Canadá. - Coordenador do Curso de Mestrado em Ortodontia da FOB - USP.

\section{Ana Maria Bolognese}

- Graduada pela Universidade Federal do Rio Grande do Sul, UFRGS.

- Doutora em Ortodontia pela Universidade Federal do Rio de Janeiro, UFRJ.

- Pós-Doutorado pela Northwestern University, NU, Estados Unidos.

- Professora Titular do departamento de Odontologia da Universidade Federal do rio de Janeiro.

- Coordenadora da pós-graduação em Ortodontia da Universidade Federal do Rio de Janeiro. menor tempo que a força será aplicada no futuro fará com que estas reabsorções se tornem menores ou imperceptiveis.

É mais ou menos como a lei de "Murphy", mas poderia ser a lei da reabsorção: "Se já aconteceu, ou está acontecendo, vai continuar acontecendo, desde que cesse ou diminua a força."

\section{Estélio Zen}

- Formado em Odontologia pela Faculdade de Odontologia de Araraquara - UNESP.

- Mestre em Ortodontia pela UFRJ.

- Membro do Board Brasileiro de Ortodontia

- Membro da Sociedade Brasileira de Ortodontia

- Membro da ABOR

- Membro Internacional da American Association of Orthodontists.

- Membro da Tweed International Foundation for the Orth. Research

- Membro da WFO

- Fellow of International College of Dentists.

\section{Roberto Mario Amaral Lima Filho}

- Graduado pela Faculdade de Odontologia da Pontifícia Universidade Católica de Campinas (PUC).

- Pós graduado em Ortodontia pela Universidade de Illinois em Chicago, EUA

- Diplomado do American Board of Orthodontics. - Membro da Sociedade Brasileira de Ortodontia; American Association of Orthodontics; College of Diplomates of the American Board of Orthodontics; European Society of Orthodontics; University of Illinois - Orthodontic Alumni Association; World Federation of Orthodontics.

\section{REFERÊNCIAS}

1. BASTOS, G.K.; MUCHA, J.N. Aparelhos funcionais: uma revisão. RBO, Rio de Janeiro, v. 59, p.184-188, mai./jun., 2002

2. BOWMAN, S.J. One-stage versus two-stage treatment: Are two really necessary? Am J Orthod Dentofacial Orthop, St. Louis, v. 113, n. 1, p. 111-116, Jan. 1998

3. CONSOLARO, A. Reabsorções dentárias nas especialidades clínicas. Dental Press Ed., Maringá, 2002.

4. GIANELLY, A.A. One phase versus two phase treatment. Am J Orthod Dentofacial Orthop, St. Louis, v. 108, no. 5, p. 556559, Nov. 1995

5. TUVERSON, D.L. Orthodontic treatment using canines in place of missing maxillary lateral incisors. Am J Orthod, St. Louis, v. 88, n. 2, p.109-127, Aug. 1970

6. TUVERSON, D.L. Anterior interocclusal relations - Part 1 and Part 2. Am J Orthod, St. Louis, v. 78, n. 4, p. 361-393, Oct. 1980

7. VAN DER LINDEN, F.P.G.M. Three years Postgraduate Programme in Orthodontics: the final report of the Erasmus Project, Am J Orthod Dentofacial Orthop, St. Louis, v. 110, n. 1, p 101-107, July 1996

8. ZACHRISSON, B.U. Diferença clínica entre transplantes e implantes. R Clin Ortodon Dental Press, Maringá, v.1, n.3, p.19-23, jul./ago. 2002 